\title{
Multidrug Resistance in Acute Myeloid Leukemia: Potential New Therapeutics
}

$\mathbf{I}_{\mathrm{n}}$ multidrug resistance (MDR) is frequently, but not always, caused by the MDR1 gene product, a 170- to 180 kDa glycoprotein known as P-glycoprotein (Pgp) or human MDR1 protein (I). It is characterized by broad resistance to several structurally, chemically, and pharmacologically distinct chemotherapeutic compounds. Many theories explain how Pgp affects MDR, including the "drug pump" model, in which Pgp hydrolyzes adenosine triphosphate to actively pump drugs out of the cell $(2,3)$. As many MDR cells have been found to have

\section{See page 1546}

increased intracellular $\mathrm{pH}$ and decreased plasma membrane potentials, another explanation of the MDR mechanism of Pgp is the alteredpartition model. This model takes into account how the alterations in intracellular $\mathrm{pH}$ and membrane potential that accompany the overexpression of Pgp indirectly affect the partitioning of the drugs, but Pgp does not directly pump the drugs out of the cell (4-6). Other drug-resistance proteins, which are associated with hematologic cancers that use similar mechanisms, include the MDR-associated protein, the lung resistance protein, and the breast cancer resistance protein (7).

Received May 12, 2008; revision accepted May 16, 2008.

For correspondence or reprints contact: Jeffrey H. Weisburg, Stern College for Women, Yeshiva

University, New York, NY 10016.

E-mail: jweisburg@yahoo.com

COPYRIGHT @ 2008 by the Society of Nuclear

Medicine, Inc.

DOI: 10.2967/jnumed.107.050153
Many investigators working to improve cancer therapy have tried to use various immunologic approaches to killing cancer cells because such approaches might circumvent chemotherapeutic drug resistance. One of the assumptions of an immunologic approach is that cells that are resistant to chemotherapeutics should not be crossresistant to immunotherapy because the mechanisms of action are so widely different. Unfortunately, several groups have shown that MDR cells seem to be resistant to several forms of immunologic therapies, including complementmediated cytotoxicity $(5,6)$, immunotoxin, gelonin attached to monoclonal antibodies (mAbs) (8), interleukin 2 (9), and drug immunoconjugates (10-12).

Another immunologic treatment is the use of mAbs to deliver radioisotopes directly to the tumor cells. At the present time, the use of radiolabeled antibodies in the treatment of AML with Pgp expression has not been well studied, if at all. In this issue of The Journal of Nuclear Medicine, Kersemans et al. (13) use a strategy to overcome MDR using mAbs that have been labeled with ${ }^{111}$ In modified with a nuclear localizing sequence (NLS). They showed that the addition of the peptide sequence CGYGPKKKRKVGG, which contains the NLS PKKKRKV of SV-40 large T-antigens, allowed the antibody to be internalized and to translocate to the nucleus. Once in the nucleus, Auger electrons from the ${ }^{111}$ In were cytotoxic to the parental HL60 cell line and drug-resistant (mitoxantrone-insensitive) HL60-MX-1 cell line and to the primary AML specimens that were expressing a diversity of MDR phenotypes. These results suggest that ${ }^{111}$ In-anti-CD33 mAbs that are modified with an NLS may be a new treatment for patients who have drug-resistant myeloid leukemias.
Although there have been significant advances in the treatment of AML, only $20 \%-30 \%$ of these patients reach longterm disease-free survival (14). The addition of Pgp expression predicts an even poorer prognosis in the elderly, those patients who have relapsed, and patients with secondary AML $(11,15)$.

When considering radioimmunotherapy for the treatment of any type of cancer, one must keep in mind three important factors: the target tumor, isotope, and antibody (16). Because leukemias are easily accessible and have well-defined differentiation antigens, they are ideal for the use of radiolabeled antibodies (17). AML is characterized by the expression of CD13, CD15, CD33, and CD117 (18). CD33 is a $67-\mathrm{kDa}$ cell-surface glycoprotein found on myeloid leukemia cells and on committed myelomonocytic and erythroid progenitor cells. It is not found on lymphoid, nonhematopoietic, or mature myeloid cells, making CD33 a prime target for antibody binding $(19,20)$.

Different isotopes have been attached to antibodies based on their half-life and the type of particle they emit. For single-cell kill, with the least cytotoxicity to normal cells, the ideal isotope emission should have a path length that is the same as that of the target cells $(21) .{ }^{90} \mathrm{Y}$ and ${ }^{131} \mathrm{I}$ emit $\beta$-particles, which have a relatively long range and a low linear-energy transfer. Unfortunately, these properties make $\beta$-particles an excellent choice for solid tumors but not for hematologic cancers, in which antibodies cannot bind to all the tumors cells at sufficient levels (21). This long particle range results in the irradiation of target tumor cells as well as surrounding cells, causing normal cells to be killed. Alpha-particles, on the other hand, have a shorter range 
(about the size range of 3-5 times that of the target cells) than $\beta$-particles and a much higher linear energy transfer. Only one $\alpha$-particle is needed to cross the nucleus to induce cell death by causing double-strand breaks in the DNA, making $\alpha$-particles more efficient than $\beta$-particles at killing a single cell. The shorter range of $\alpha$-particles is beneficial in 2 ways. First, nonspecific cytotoxicity to nearby healthy cells should be reduced, and second, because the path length of $\alpha$-particles is shorter, they would be an effective single-cell killer (22). Auger electrons have a highlinear-energy transfer and an even smaller path length than do $\alpha$-particles, making Auger electrons also suitable for the treatment of hematologic cancers. High antigen densities are essential because a large number of decays is vital for strong cytotoxicity (23). The dose, meaning what kills the cells, is dependent on the energy of the particle and the half-life. Unlike $\alpha$ - and $\beta$-radiation, Auger emitters need to be attached to the individual tumor cells and enter the nucleus. Optimum results with Auger electron emitters were seen when they were bound to the DNA, causing doublestand breaks (24).

In the study by Kersemans et al. (13), the authors were able to specifically target the nucleus of the HL-60 and HL-60-MX-1 cells by the addition of the NLS onto the antibodies, making the increase in nuclear radioactivity 4- to 6-fold greater than that of the antibodies without the NLS. With this increase in nuclear localized radiation, survival of the targeted cells was significantly decreased. The authors also saw this increased cytotoxicity in the primary AML samples that expressed the different types of MDR transporters (13). This result is exciting because other methods to overcome drug resistance in AML have fallen short. Unsuccessful results have been observed in clinical trials using specific MDR1 inhibitors such as PSC-883 or quinine $(25,26)$.

Given the dependence of cytotoxicity on high levels of antibody binding, it is necessary to determine whether the samples of patients with AML have levels of antigen that are comparable to those expressed in the cell lines. Kersemans et al. (13) reported that the HL-60 and HL-60-MX-1 cells contained 3-4 × $10^{4}$ CD33 per cell. With this number of sites per cell, they determined that at a specific activity of $8 \mathrm{MBq} / \mu \mathrm{g}, 10 \%$ of the radioactivity is localized to the cell surface, $70 \%$ is in the cytoplasm, and $20 \%$ is in the nucleus. It has been previously reported that myeloid and monocytic leukemias contain only $1 \times 10^{4} \mathrm{CD} 33$ per cell (27). A possible drawback with CD33 as the target is that these levels can be decreased among different cells lines and in patient samples, preventing enough Auger electrons from entering the nucleus to kill the cell. To overcome these lower CD33 levels of different targets, a higher specific activity may be needed to increase the percentage inside the nucleus. However, this could reduce immunoreactivity. Another aspect to consider is the pharmacokinetics of the antibody with the attached polypeptide chain; are they different from those of the antibody alone? Pharmacokinetics must be determined for these novel constructs.

The attachment of the NLS to the antibody may invigorate interest in radioimmunotherapy and seems to have many applications. The use of $\alpha$-emitters on NLS-tagged antibodies is noteworthy. The NLS-tagged antibodies could bring the isotope directly to the nucleus to ensure a "direct hit." Possible problems associated with $\alpha$-particle emitters such as ${ }^{212} \mathrm{Bi}$ and ${ }^{213} \mathrm{Bi}$ are the short half-lives, making it difficult for an antibody to reach the tumor cells in time to have an effect, and the longer path lengths, affecting some normal bystander cells (21). The issue of short half-life could be solved by using ${ }^{225} \mathrm{Ac}$, which has a half-life of $10.5 \mathrm{~d}$ (28). To reduce the killing of normal cells, the NLS on the antibody would bring the $\alpha$-particle directly to the nucleus of the cancerous target, and less antibody would be required.

The addition of the NLS to a radiolabeled antibody, allowing it to enter the nucleus and increase the killing of multidrug-resistant cells, is promising. The results demonstrated in the article by Kersemans et al. (13) show that there may be a treatment to overcome MDR in AML and perhaps other types of hematologic cancers.

\section{Jeffrey $H$. Weisburg Yeshiva University New York, New York}

\section{REFERENCES}

1. Chang G. Multidrug resistance ABC transporters. FEBS Lett. 2003;555:102-105.

2. Croop JM, Guild B, Gros P, Houseman DE. Genetics of multidrug resistance: relationship of a coned gene to the complete multidrug resistant phenotype. Cancer Res. 1987;47:5982-5988.

3. Hamada $\mathrm{H}$, Tsuruo $\mathrm{T}$. Characterization of the ATPase activity of the $\mathrm{Mr} 170,000$ to 180,000 membrane glycoprotein (P-glycoprotein) associated with multidrug resistance in K562/ADM cells. Cancer Res. 1988;48:4926-4932.

4. Wadkins RM, Roepe PD. Biophysical aspects of P-glycoprotein-mediated multidrug resistance. Int Rev Cytol. 1997;171:121-165.

5. Weisburg JH, Curcio M, Caron PC, et al. The multidrug resistant phenotype confers immunological resistance. J Exp Med. 1996;183:2699-2704.

6. Weisburg JH, Roepe PD, Dzekunov S, Scheinberg DA. Intracellular $\mathrm{pH}$ and multidrug resistance regulate complement-mediated cytotoxicity of nucleated cells. J Biol Chem. 1999;274:10877-10888.

7. Hirose M, Hosoi E, Hamano S, Jalili A. Multidrug resistance in hematological malignancy. $\mathrm{J} \mathrm{Med}$ Invest. 2003;50:126-135.

8. McGrath MS, Rosenblum MG, Philips MR, Scheinberg DA. Immunotoxin resistance in multidrug resistant cells. Cancer Res. 2003;63:72-79.

9. Drach J, Gsur A, Hamilton G, et al. Involvement of P-glycoprotein in the transmembrane transport of IL-2, IL-4 and interferon- $\gamma$ in normal human T lymphocytes. Blood. 1996;88:1747-1754.

10. Naito K, Takeshita A, Shigeno K, et al. Calicheamicin-conjugated humanized anti-CD33 monoclonal antibody (gemtuzumab, zogamicin, CMA-676) shows cytocidal effect on CD33-positive leukemia cell lines, but is inactive on P-glycoprotein-expressing sublines. Leukemia. 2000;14:1436-1443.

11. Linenberger ML, Hong T, Flowers D, et al. Multidrugresistance phenotype and clinical response to gemtuzumab ozogamicin. Blood. 2001;98:988-994.

12. Sievers EL, Larson RA, Stadtmauer EA, et al. Efficacy and safety of gemtuzumab ozogamicin in patients with CD33-positive acute myeloid leukemia in first relapse. J Clin Oncol. 2001;19:32443254.

13. Kersemans V, Cornelissen B, Minden MD, Brandwein J, Reilly RM. Drug-resistant AML cells and primary AML specimens are killed by ${ }^{111}$ In-anti-CD33 monoclonal antibodies modified with nuclear localizing peptide sequences. $\mathrm{J} \mathrm{Nucl}$ Med. 2008;49:1546-1554.

14. Cassileth PA, Harrington DP, Appelbaum FR, et al. Chemotherapy compared with autologous or allogenic bone marrow transplantation in the management of acute myeloid leukemia in first remission. N Engl J Med. 1998;339:1649-1656. 
15. Legrand O, Simonin G, Perrot J-Y, et al. Pgp and MRP activities using calcein-AM are prognostic factors in adult acute myeloid leukemia patients. Blood. 1998;91:4480-4488.

16. Goldenberg DM. Target therapy of cancer with radiolabeled antibodies. $J$ Nucl Med. 2002;43:693713.

17. Burke JM, Jurcic JG. Radioimmunotherapy of leukemia. Adv Pharmacol. 2004;51:185-208.

18. Todd WM. Acute myeloid leukemia and related conditions. Hematol Oncol Clin North Am. 2002; 16:301-319.

19. Andrews RG, Torok-Storb B, Bernstein ID. Myeloid-associated differentiation antigens on stem cells and their progeny identified by monoclonal antibodies. Blood. 1983;62:124-132.

20. Griffin JD, Linch D, Sabbath K, et al. A monoclonal antibody reactive with normal and leukemic human myeloid progenitor cells. Leuk Res. 1984;8: 521-534.

21. Mattes MJ. Radionuclide-antibody conjugates for single-cell cytotoxicity. Cancer. 2002;94(4 suppl): $1215-1223$.

22. Burke JM, Jurcic JG, Scheinberg DA. Radioimmunotherapy for acute leukemia. Cancer Control. 2002;9:106-113.

23. Michel RB, Andrews PM, Castillo ME, Mattes MJ. In vitro cytotoxicity of carcinoma cells with ${ }^{111} \mathrm{In}$ labeled antibodies to HER-2. Mol Cancer Ther. 2005;4:927-937.

24. Buchegger F, Perillo-Adamer F, Dupertuis YM, Delaloye AB. Auger radiation target into DNA: a therapy perspective. Eur $\mathrm{J} \mathrm{Nucl} \mathrm{Med} \mathrm{Mol}$ Imaging. 2006;33:1352-1363.

25. van der Holt B, Lowenberg B, Burnett AK, et al. The value of the MDR1 reversal agent PSC-833 in addition to daunorubicin and cytarabine in the treatment of elderly patients with previously untreated acute myeloid leukemia (AML), in relation to MDR status at diagnosis. Blood. 2005;106:26462654.

26. Solary E, Drenou B, Campos L, et al. Quinine as a multidrug resistance inhibitor: a phase 3 multicentric randomized study in adult de novo acute myelogenous leukemia. Blood. 2003;102:1202-1210.

27. Tanimoto M, Scheinberg DA, Cordon-Cardo C, et al. Restricted expression of an early myeloid and monocytic cell surface. Leukemia. 1989;3:339348.

28. Miederer M, McDevitt MR, Sgouros G, et al. Pharmacokinetics, dosimetry, and toxicity of the targetable atomic generator, ${ }^{225} \mathrm{Ac}-\mathrm{HuM} 195$, in nonhuman primates. J Nucl Med. 2004;45:129137.

\section{Erratum}

In the article "SPECT/CT," by Buck et al. (J Nucl Med. 2008;49:1305-1319), the legends of Figures 1, 5, and 6 contain errors. In the legend of Figure 1, "99m Tc-iodobenzamide" should be "123 I-ioflupane (DaTSCAN [GE Healthcare])." In the legend of Figure 5, panel B is described as a ${ }^{99 m} \mathrm{Tc}-\mathrm{MIBI}$ scan but is in fact a ${ }^{99 \mathrm{~m}} \mathrm{Tc}-$ pertechnetate scan. In the legend of Figure 6, "99mTc-MIBG" should be "123I-MIBG." The authors regret the errors. 